\title{
Reif für die Insel
}

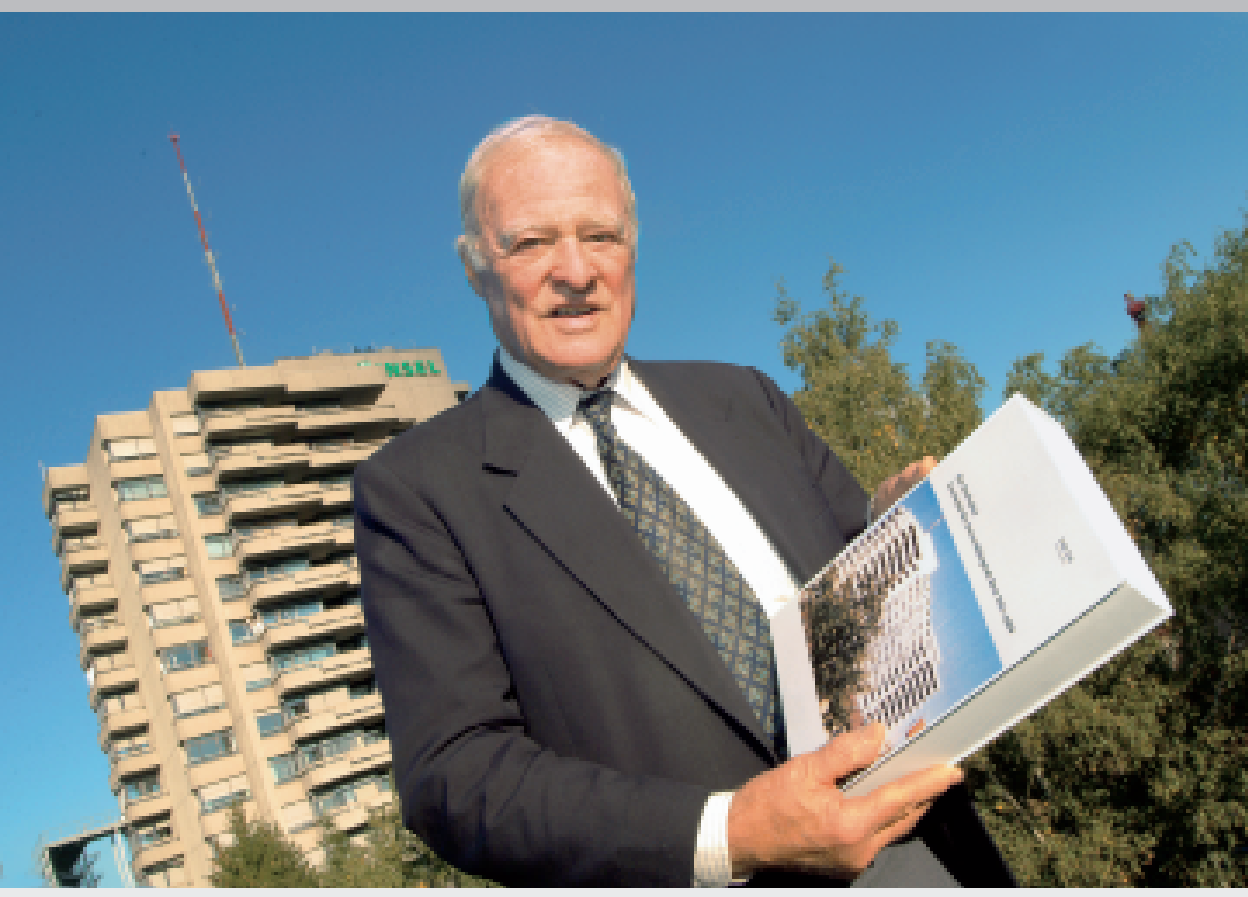

Der Herausgeber und sein Werk: Fritz Leu vor dem Inselspital.

Fritz Leu scheint zu den Menschen zu gehören, die über einen unerschöpflichen Fundus an Anekdoten verfügen. Wenn er einem lebhaft erzählend in der Cafeteria der «Insel» gegenübersitzt, hoch über den Dächern von Bern, den Schalk im Auge, würde man nicht vermuten, dass er seit 16 Jahren pensioniert ist. Wobei das Wort Ruhestand in seinem Fall definitiv ein Fehlgriff wäre. Der jüngste Beweis und Anlass des Besuchs an seiner ehemaligen Wirkstätte: Ein fast 600 Seiten starker, rund $3 \mathrm{~kg}$ schwerer «Wälzer» über das Inselspital*, der seiner Initiative entsprang und den er als Herausgeber und Hauptautor entscheidend geprägt hat.

Dem Konzept Leus entsprechend stammen die Beiträge zum Buch fast ausschliesslich von «Insidern», Personen also, die die Geschichte des Inselspitals im vergangenen halben Jahrhundert miterlebt und mitgestaltet haben. Damit steht es in einem spannenden Gegensatz zur 1954 anlässlich des 600-Jahre-Jubiläums des Inselspitals erschienenen, als Standardwerk geltenden Arbeit der «Externen», Hermann Rennefahrt und Erich Hintsche, die den grössten Teil ihrer Informationen den Quellensammlungen des Staatsarchivs entnahmen.

Bezüglich «Insidertum» - das in diesem Kontext von negativen Konnotationen frei ist - darf Fritz Leu in Sachen Inselspital eine unanfechtbare Führungsposition zugesprochen werden. Ab 1958 war er als Vizedirektor, später als Direktor der «Insel» an vorderster Front dabei, begleitete und führte das Spital durch eine Epoche, die «unvorstellbare Veränderungen» mit sich brachte. Das «Spital für Bauern und aus Privatkliniken abgeschobene Sterbende» wuchs in dieser Zeit zu einem höchst komplexen Organismus, in dem sowohl in den einzelnen medizinischen Disziplinen als auch in der interdisziplinären Zusammenarbeit Spitzenleistungen erbracht werden. Mitautor Hans Jakob Peter, seit 1995 Chefarzt der Medizinischen Abteilung Anna Seiler am Inselspital, zeichnete im Rahmen der Buchpräsentation die Auswirkungen des exponentiellen Wissenszuwachses und des technologischen Fortschritts der letzten 50 Jahre auf die spitalärztliche Tätigkeit am Beispiel der Abklärung einer «Lungenverschattung» eindrücklich nach. Ein hohes fachliches Niveau wird von der Medizin am Inselspital selbstredend auch in Zukunft erwartet werden, als genauso wichtig stuft Peter jedoch den Anspruch der Patienten auf Geborgenheit und Vertrauen ein.

Wie Leu selbst treffend feststellte, ist «Das Inselspital» aufgrund seines Umfangs und der gebotenen Informationsfülle nicht in erster Linie ein Buch, das man liest, sondern in dem man liest. Und, so wäre zu ergänzen, das man fasziniert anschaut. Das reichhaltige Bildmaterial bietet spannende Einblicke in die Spitalgeschichte, gibt den prägenden Figuren aus den verschiedensten Bereichen im wahrsten Sinne des Wortes ein Gesicht und hält auch manche Überraschung bereit. In welchem Spitalarchiv findet sich schon ein Bild des Vizedirektors, der dem Pflegepersonal bei der Verteilung der Mahlzeiten zur Hand geht?

Bruno Kesseli \footnotetext{
Weber; 2006. 575 Seiten, Fr. 80 ISBN 978-3-309532-36-5.

Leu F (Hrsg.). Das Inselspital. Geschichte des Universitätsspitals
} 